\title{
Application of Ethnobotanical Indices on the Use of Traditional Medicines against Common Diseases
}

\author{
Imran Khan, ${ }^{1}$ Naser M. AbdElsalam, ${ }^{2}$ Hassan Fouad, ${ }^{2,3}$ Akash Tariq, ${ }^{1}$ \\ Riaz Ullah, ${ }^{4}$ and Muhammad Adnan ${ }^{1}$ \\ ${ }^{1}$ Department of Botany, Kohat University of Science and Technology, Kohat 26000, Pakistan \\ ${ }^{2}$ Riyadh Community College, King Saud University, Riyadh 11437, Saudi Arabia \\ ${ }^{3}$ Department of Chemistry, Biomedical Engineering Department, Faculty of Engineering, Helwan University, \\ P.O. Box 11792, Helwan, Egypt \\ ${ }^{4}$ Department of Chemistry, Government College Ara Khel, FR Kohat, Khyber Pakhtunkhwa 26000, Pakistan
}

Correspondence should be addressed to Muhammad Adnan; ghurzang@hotmail.com

Received 22 February 2014; Accepted 24 April 2014; Published 20 May 2014

Academic Editor: Rainer W. Bussmann

Copyright (C) 2014 Imran Khan et al. This is an open access article distributed under the Creative Commons Attribution License, which permits unrestricted use, distribution, and reproduction in any medium, provided the original work is properly cited.

The present study was aimed at documenting the detailed ethnomedicinal knowledge of an unexplored area of Pakistan. Semistructured interviews were taken with 55 informants randomly chosen regarding detailed ethnomedicinal and sociocultural information. The study exposed 67 medicinal plant species used to prepare 110 recipes and the major modes of herbal formulation were decoction and powdering $(20 \%$ each). The disease categories with the highest Fic values were gastrointestinal and dermatological (0.87 each). The study determined 3 plant species, i.e., Acacia modesta Wall., Caralluma tuberculata R.Br., and Withania somnifera (L.) Dunal with a FL of 100\%. DMR results showed that Olea ferruginea (Sol.) Steud. ranked first, Morus alba L. ranked second, and Melia azedarach L. ranked third. Among the 55 informants, the male concentration was high (61\%) and most of them were over 40 years old while a leading quantity of respondents (45\%) was uneducated. There is a dire need to take necessary steps for the conservation of important medicinal plants by inhibiting overgrazing and providing alternate fuel resources. Young generations should be educated regarding the importance of ethnomedicinal knowledge and plants with high Fic and FL values should be further checked chemically and pharmacologically for future exploration of modern medicine.

\section{Introduction}

Medicinal plants offer a real substitute in developing countries for the treatment of human and animal ailments [1]. Ethnomedicine is often the single easily reached and affordable therapy available. The world market for herbal medicines based on traditional knowledge is now estimated at US\$ 60 billion [2]. Plant-based traditional medicine plays a key role in the development of novelties in drug discovery [3].

Pakistan has a rich medicinal plants history having more than 600 plants being used traditionally for medication [4]. The majority of the medicinal plants are confined to northwest regions of Pakistan due to the presence of Himalayas, Karakoram, Sulaiman, and Hindu Kush mountain ranges [5] that lie in association with Pak-Afghan border. Both countries Pakistan and Afghanistan share almost 2,500 kilometers of boundary, called Durand Line, which was demarcated in 1893 following an agreement between the British Empire and the Afghan king [6]. The Durand Line separates Pashtun ethnic group in the Pak-Afghan border areas. Culturally, Pashtuns represent the majority of the populace of Afghanistan and also have significant population in Pakistan. The local language of southeastern Afghanistan and northwestern Pakistan Pashtun ethnic group is Pashtu [7]. The majority of the northwest areas of Pakistan living in the proximity to border region are rural in nature with high illiteracy rate and greatly depend on medicinal plants for primary health care and for generating income. In Pakistan, various ethnobotanical 


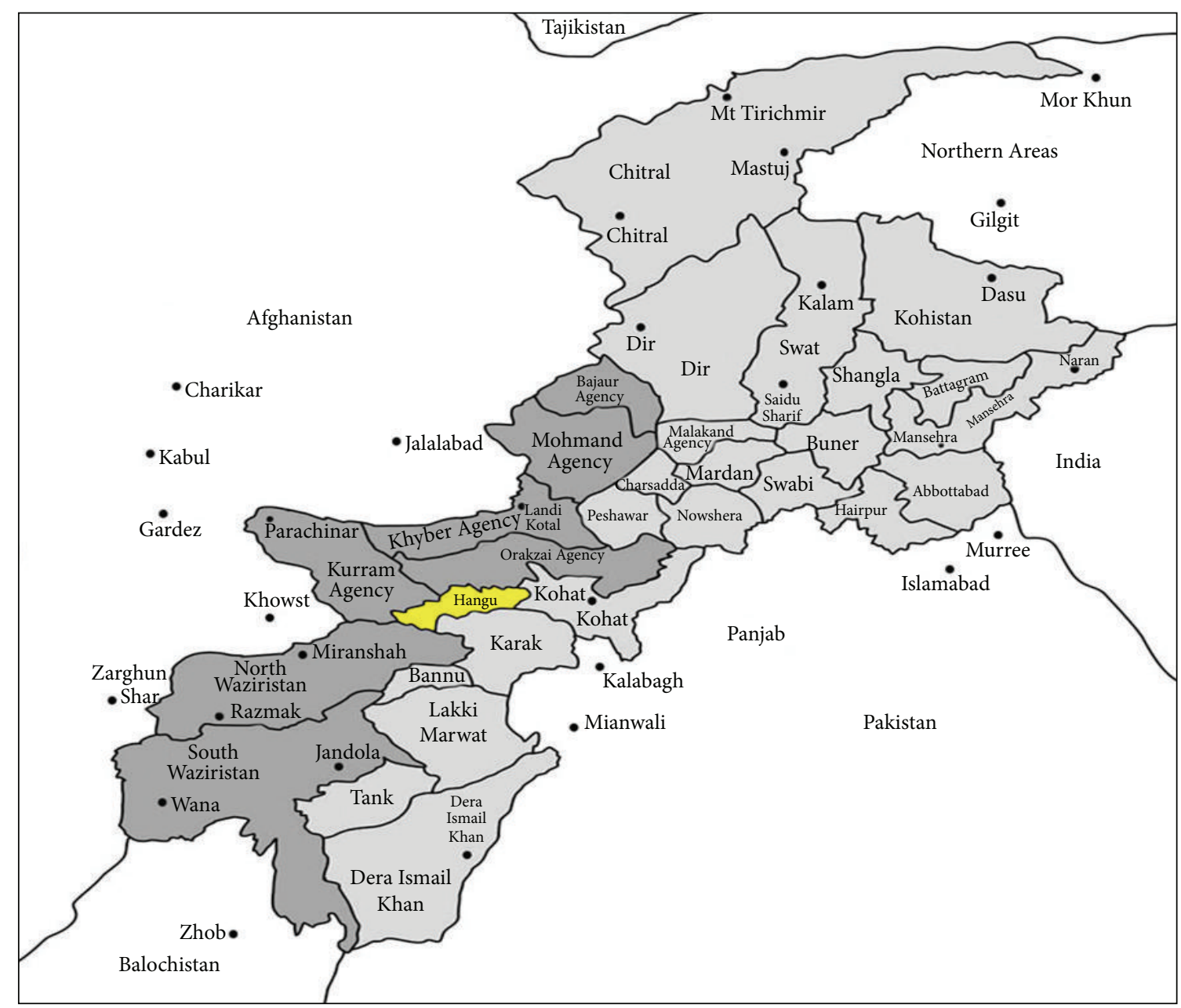

FIgURE 1: Map of the study area.

studies have been conducted in the different regions $[8,9]$ (Akhtar et al. [9]; Mussarat et al. [10], Hassan et al. [11]; and Begum et al. [12]). Most of the ethnobotanical studies in Pakistan have documented just the uses of medicinal plants. Almost no studies have been documented on detailed ethnomedicines preparations in the border region villages. The current research is the first effort to provide a thorough overview on the ethnomedicines employed by conventional healers and their detailed appliance in the region. This research will offer baseline data for more comprehensive studies on effectiveness and security of these preparations, as well as the potential applications in the communal health system. Moreover, the region is very rich in medicinal plants due to its conductive climate but this area has never been touched so far. Therefore, it is imperative to document the vegetation and detailed home-grown information of people about medicinal plants of this area before it is lost due to changing cultures. The purpose of this study is to assess traditional medicinal plant knowledge specifically with regard to the traditional healer's demographic characteristics such as gender, age, and source of income and to document the knowledge and the uses of medicinal plants used by the traditional healers in the Hangu region, Pakistan, to provide baseline data for future pharmacological and phytochemical studies by the application of ethnobotanical indices.

\section{Material and Methods}

2.1. Study Area. The present study was conducted in Hangu district located in north of Khyber Pakhtunkhwa, Pakistan, near the border region with Afghanistan (Figure 1). Hangu is situated at 33.53 North latitude, 71.06 East longitude, and $858 \mathrm{~m}$ above the sea level comprising a total area of $1,097 \mathrm{~km}^{2}$ and total population of 314,529 [13]. The dominant vegetation in the study area is Acacia modesta, Olea ferruginea, Dodonaea viscosa (L.) Jacquin, Acacia nilotica L., Periploca aphylla Decne., Melia azedarach, and Morus alba. The temperature of the area rises gradually from the month of January to June and then slowly turns down up to December. The summer season is modest and warm but June and July are the hottest months. The mean highest temperature is $8.8^{\circ} \mathrm{C}$ and mean 
lowest temperature is $7^{\circ} \mathrm{C}$ in the months of December and January. This district also produces wheat and maize as major crops. The area is rural in nature and the majority of the population is illiterate and they are also deprived of modern health services; hence the locals rely on medicinal flora of the region for the healthcare and to balance their low earnings as well [14]. The inhabitants mostly rely on timber for fuel purposes due to lack of modern fuel resources [13].

2.2. Data Collection. Field work was carried out from October 2012 to October 2013. Data was collected by making total eight frequent visits to the study area in four different seasons. Total 250 informants were recommended by knowledgeable elders, local authorities, and development agents. Out of 250 , we have randomly selected 55 (34 men and 21 women) out of the total identified key informants. The selected informers were local inhabitants of the area aged between 20 and 89 years. Ethnobotanical survey was taken to gather information on traditional plants utilized by the local healers for the treatment of human ailments in the district following standard methods $[15,16]$. The survey was done by using proper semistructured interviews and group discussions as well. A checklist of questions was prepared in English language for undertaking interviews and discussions. The questionnaire contained no strict questions and informants were allowed to speak spontaneously and without pressure. Key questions about medicinal plants were on local name of a particular medicinal plant, types of disease treated, mode and method of remedy preparation, parts of the plants used, use of fresh or dry plant parts, use of single or mixture of plants for remedy preparation, mode of administration, and dose requirement. Sociocultural information about informants was also collected during interview. The informants were interviewed in their local language Pashto. Ethically written acceptance was collected from the main office of the district and also from the head person of the village. The purpose of the present study was also explained to each informant in order to remove their hesitation and to encourage them that their knowledge will be a great contribution in the scientific literature.

2.3. Specimen Collection and Identification. The reported medicinal plants were collected from natural vegetation and home gardens during the field walks and habits of the plants were listed. The collected voucher specimens were taken to the Herbarium of Kohat University of Science and Technology, Kohat, Pakistan. Specimen identification and confirmation were undertaken by using Flora of Pakistan and taxonomic experts. Specimens with their label were stored at the Herbarium of Kohat University of Science and Technology, Kohat, Pakistan.

2.4. Data Organization. The collected ethnobotanical data were entered into Excel spreadsheet 2007 and summarized using graphical statistical methods such as percentages. The habit of the plants was categorized into three categories, that is, herbs, shrubs, and trees. The part used by the healers for the preparation of ethnomedicines was grouped under
11 classes, that is, leaves, whole plant, root, fruit, bark, and so forth. Human ailments treated in the study area were categorized into 18 categories like gastrointestinal, dermatological, skeletomuscular, antidiabetic, and so forth. Route of administration was divided into oral, dermal, and nasal. The basic categorization using questionnaire data regarding informants' sex, age groups, educational status or literacy rate, and occupation was also carried out.

\section{Data Analyses}

3.1. Informant Consensus Factor (Fic). For the analysis of the general use of plants, factor informant consensus (Fic) was used to highlight plants of particular cultural relevance and agreement in the use of plants. Informants' consensus within a community and between cultural groups indicates which plants are widely used and thus aids in the selection of plants for pharmacological and phytochemical studies [17]. In order to use this tool, illnesses were classified into categories, as plants with high Fic are likely to be more pharmacologically efficient as compared to plants with low Fic [18]. Fic values lie between " 0.00 and 1.00". Fic values are always greater when single or few plants are documented to be used by large number of respondents to cure a specific disease, while low Fic values give an indication that informants do not agree over which plant to use $[19,20]$.

The Fic can be calculated using the formula as follows:

$$
\text { Fic }=\frac{\text { nur }- \text { nt }}{\text { nur }-1},
$$

where Fic $=$ informants consensus factor, nur $=$ number of use citation in each category, and $\mathrm{nt}=$ number of species used.

3.2. Fidelity Level ( $F L)$. Fidelity level is useful for identifying the key informants' most preferred species used for treating certain ailments. The medicinal plants that are widely used by the local people have higher FL values than those that are less popular. Fidelity level shows the percentage of informants claiming the use of a certain plant species for the same major purpose. This is designed to quantify the importance of the species for a given purpose. Before calculating the values of FL all of the ailments that were reported are grouped into major classes [21]. FL value was estimated using the formula $\mathrm{FL}=\mathrm{Ip} / \mathrm{Iu} \times 100$, where Ip is the number of respondents who reported the utilization of medicinal plants for a specific main ailment and Iu is the total number of respondents who mentioned the same plant for any ailment [22]. It is assumed that those medicinal plants which are plants that are used in some recurring manner for the same disease category are more likely to be biologically active [18].

3.3. Direct Matrix Ranking (DMR). DMR $[15,16]$ was used to compare the use diversity of given plant species based on the data collected from the respondents. Total eight informants were selected for the collection of DMR data. Selected informants were asked to assign use values $(5=$ best, $4=$ very good, $3=$ good, $2=$ less used, $1=$ least used, and 0 
$=$ not used) to each species. The values (average scores) given to each medicinal plant were summed up and ranked.

\section{Result and Discussion}

4.1. Medicinal Plants Reported. The study revealed 67 medicinal plant species belonging to 55 genera and 39 families consisting of 65 angiosperms and 2 gymnosperms in Hangu district (Table 1). The investigated region has a rich diversity of medicinal plants and provides a conductive habitat and ideal climatic conditions for their growth as shown by the presence of 67 medicinal plant species. The majority of the medicinal plants reported were herbs (43\%) followed by shrubs (30\%) and trees (27\%). The high usage of herbs in the study area could be an indication of their abundance and it might also be due to the fact that they are easily accessible near household and might have high effectiveness in the treatment of ailments in comparison to other growth forms [23]. The common use of herbs for medicinal purposes is also reported from other parts of the world $[24,25]$. The dominant families in the study area were Asteraceae and Solanaceae represented by the highest number of species (4 species each, 6\%) followed by Euphorbiaceae, Moraceae, Oleaceae, and Lamiaceae (3 species each, 4.47\%). Other families with low number represented by 2 species each Amaranthaceae, Acanthaceae, Alliaceae, Poaceae, Papilionaceae, Zygophyllaceae, Arecaceae, and Rhamnaceae, while the remaining 22 families had only single species representation. The wider utilization of species from dominant families like Asteraceae and Solanaceae might relate to the presence of effective bioactive ingredients against ailments [26]. Our results are in line with other ethnomedicinal studies conducted in other regions of Pakistan $[9,27]$ where traditional healers mostly use Solanaceae and Asteraceae members for the preparation of ethnomedicines.

4.2. Common Ailments in the Study Area. Traditional healers use 67 medicinal plants for the treatment of a variety of disorders in the studied region. These were grouped into 18 major disease categories like gastrointestinal, dermatological, antipyretic, blood disorders, and so forth. The natives of the region use total 25 plant species for gastrointestinal disorders followed by 13 for dermatological infections. The results are in agreement with other studies conducted in other parts of Pakistan and other countries [28, 29]. The use of a large number of medicinal plants for the treatment of gastrointestinal and dermatological ailments in the region could be due to the high occurrence of these problems in the study area due to bad hygiene, fuel wood smoke inside houses, and other factors like water and air pollution [30]. Informant consensus results have also shown a high degree of consensus for gastrointestinal and dermatological (0.87 each) ailments, which were followed by blood disorder like diabetes (0.84) (Table 2). The highest plant use citation was for gastrointestinal (200) followed by dermatological ailments (100). High Fic value gives an indication that these diseases are more prevalent in the Hangu region that might be due to the poor socioeconomic and sanitary conditions of

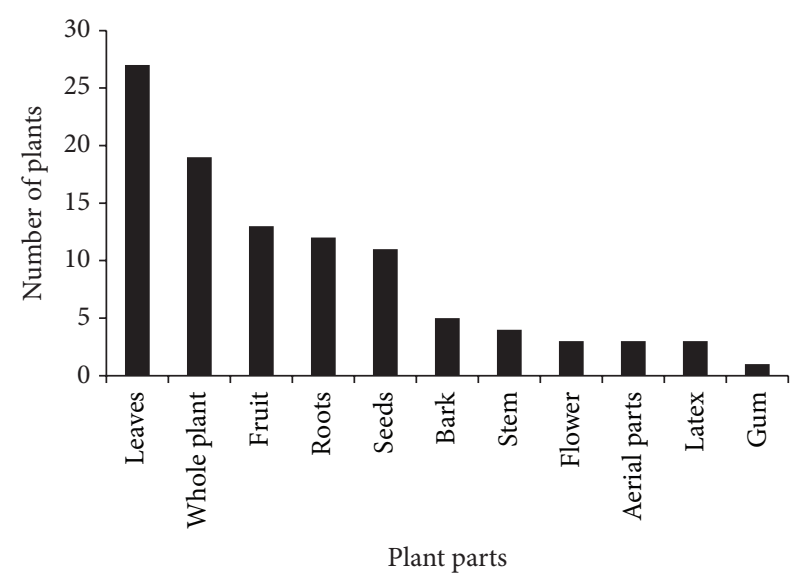

FIGURE 2: Plant parts used for remedy preparation.

the people. According to Heinrich et al. [19], high Fic values are very useful in the selection of specific plants for further search of bioactive compounds. The medicinal plants that are widely used by the local people have higher FL values than those that are less popular. The present study revealed 20 medicinal plants having high FL value. FL values in this study varied from $1.0 \%$ to $100 \%$. The study determined 3 plant species (Acacia modesta, Caralluma tuberculata, and Withania somnifera) with a FL of $100 \%$ followed by 7 (Allium sativa L., Mentha arvensis L., Mentha longifolia L., Cannabis sativa L., Punica granatum L., Morus alba, and Morus nigra L.) species with more than $90 \%$ and less than $100 \%$, which might be taken as a signal of the excellent curative potential of the plants (Table 3). All these plants that reported higher FL values are not only being frequently used in study region but also in other regions of the Pakistan [8, 31]. These plants possess different phytochemicals responsible for their therapeutic actions. Withania somnifera contains compound withanolides, which are believed to account for its extraordinary medicinal properties [32]. Caralluma tuberculata contains pregnane glycosides, flavones glycosides, and other phytochemical responsible for its antidiabetic and anticancer activities [33]. It is understood that plants used in recurring manner are more phytochemically active [16]. High FL value plants might be selected for further chemical screening to investigate the bioactive compounds responsible for their high curative potential $[34,35]$.

4.3. Ethnomedicinal Preparations. Traditional healers mostly use leaves (40\%) of the plants followed by whole plant (28\%) and fruits (19\%) for the preparation of different ethnomedicines. The current investigation showed (Figure 2) that leaves $(40 \%)$ are the most collected plant parts for medicinal purposes. This might be due to easy availability and containing high amount of chemicals and could be easily extracted and used in different forms but it needs biochemical analysis and pharmaceutical screening to crosscheck the local information. Use of leaves of plants does not cause damaging effect on the plant life cycle as compared with other parts like roots and flower, and so forth. Due to 


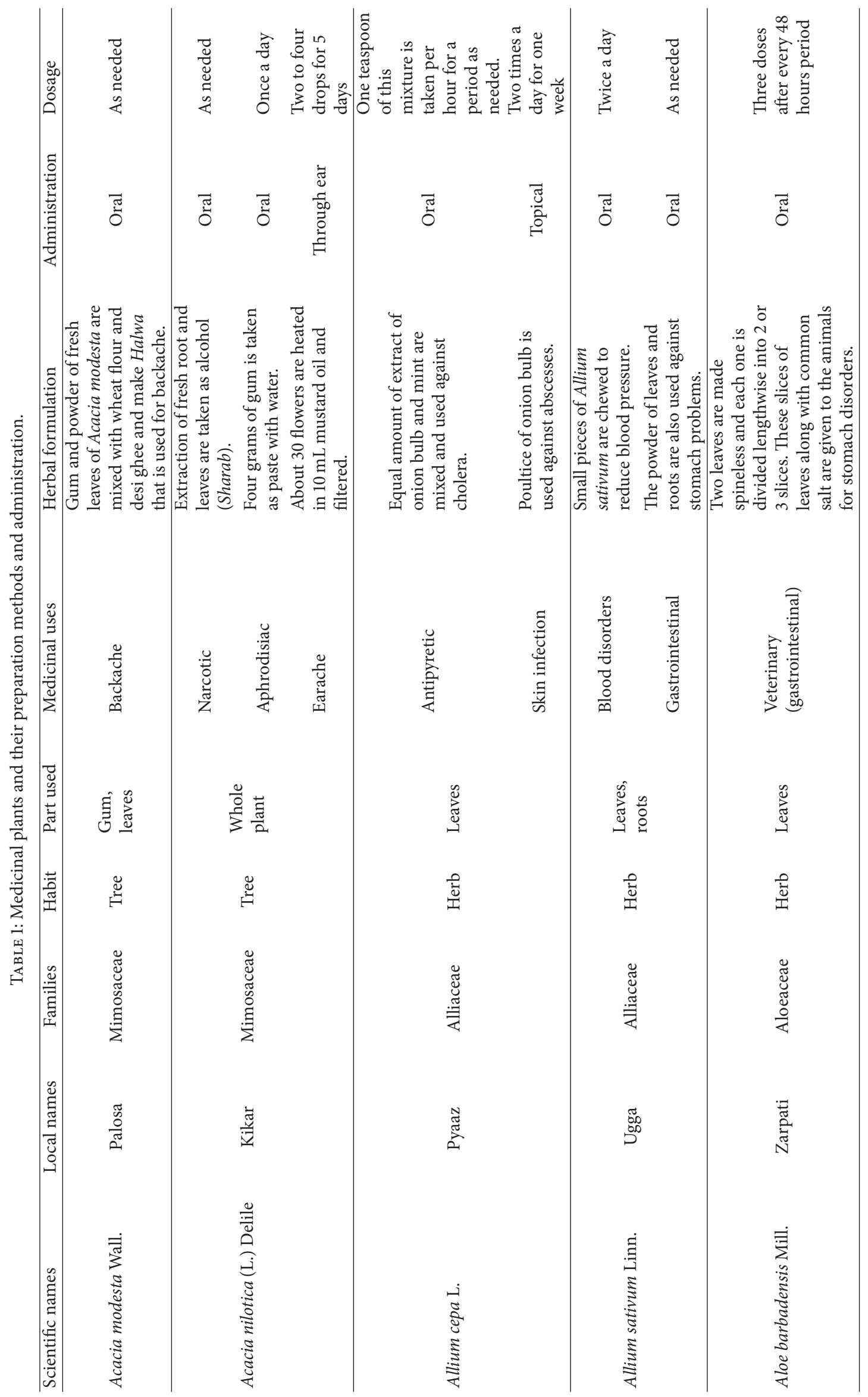




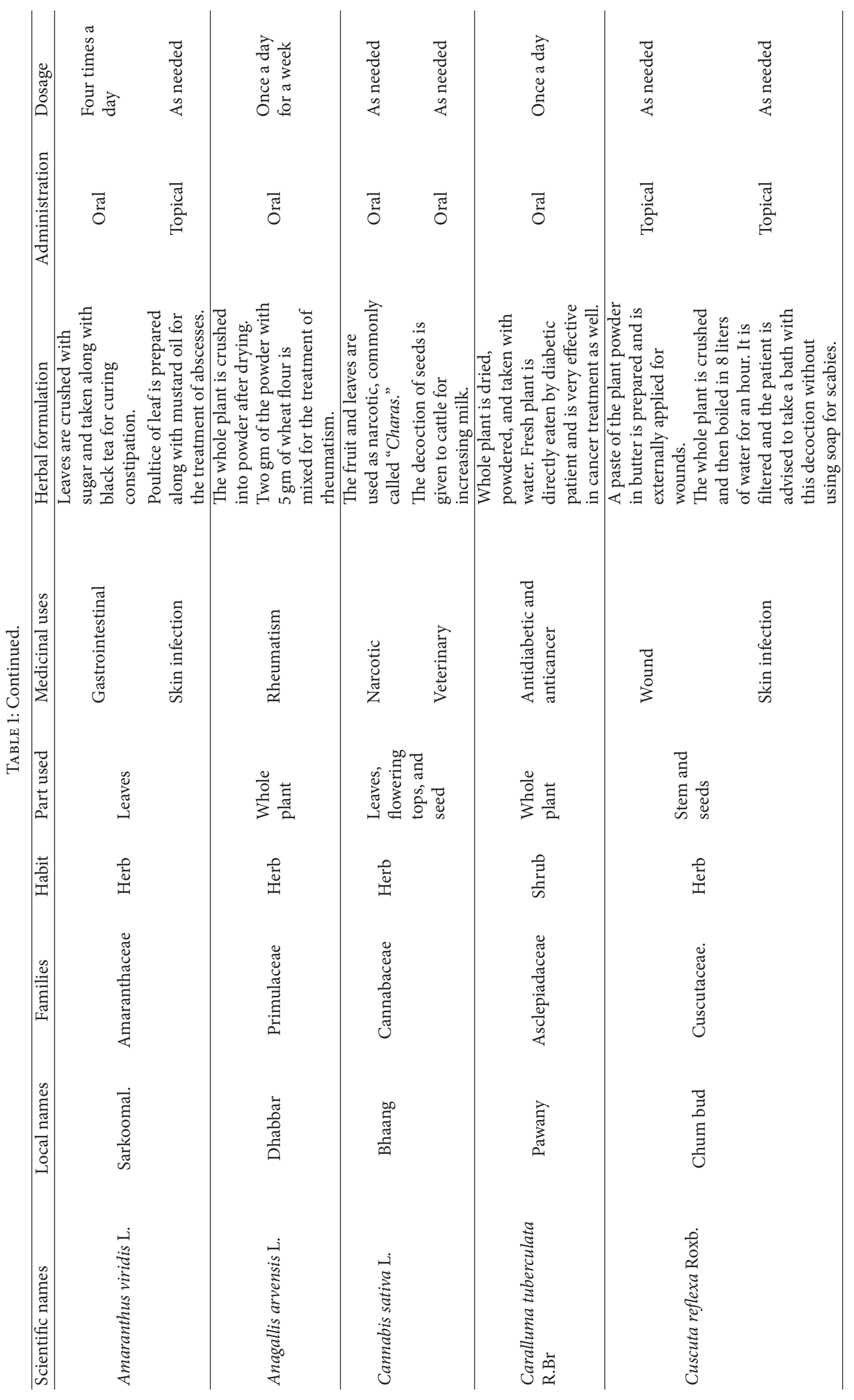




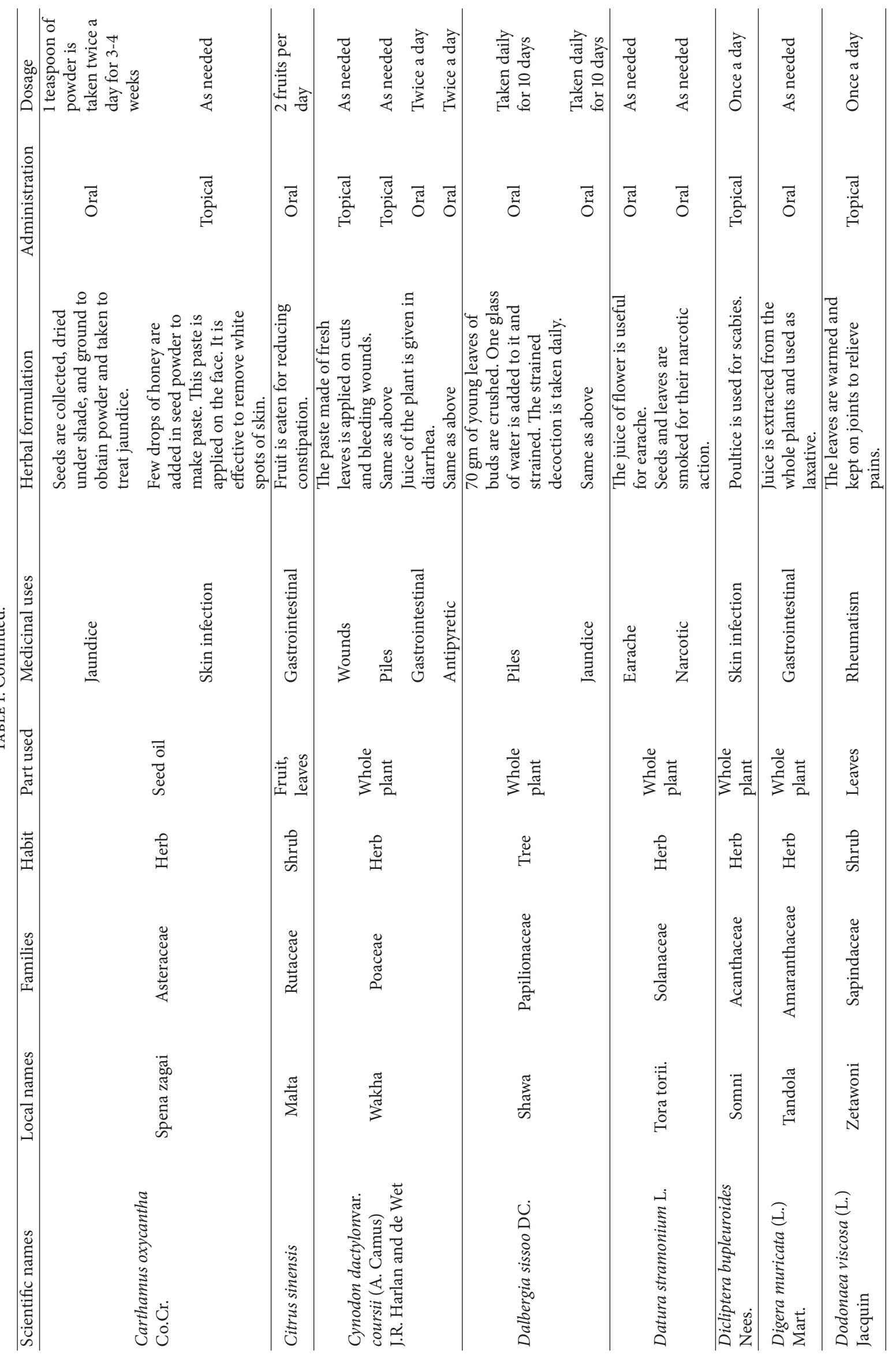




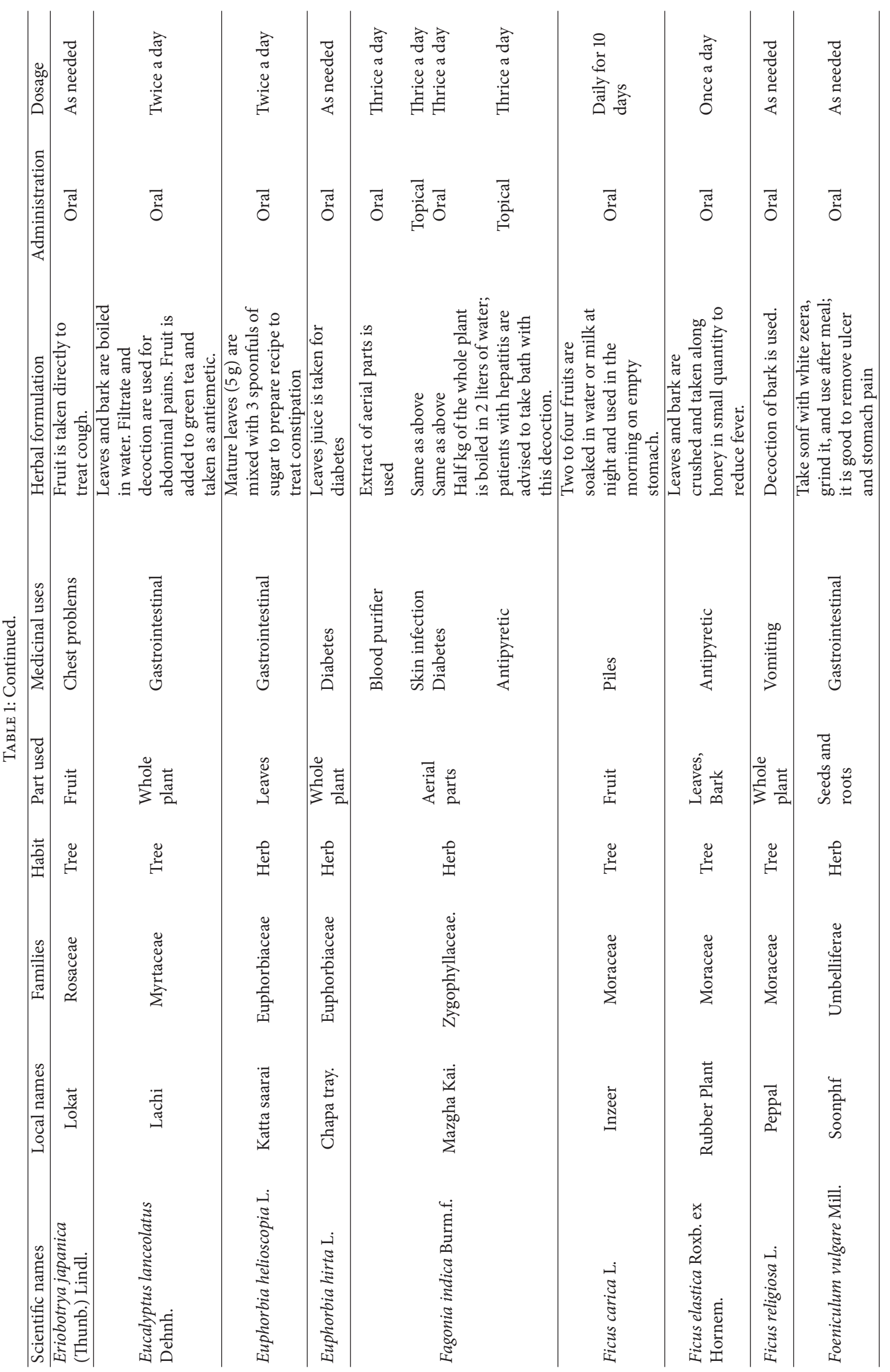




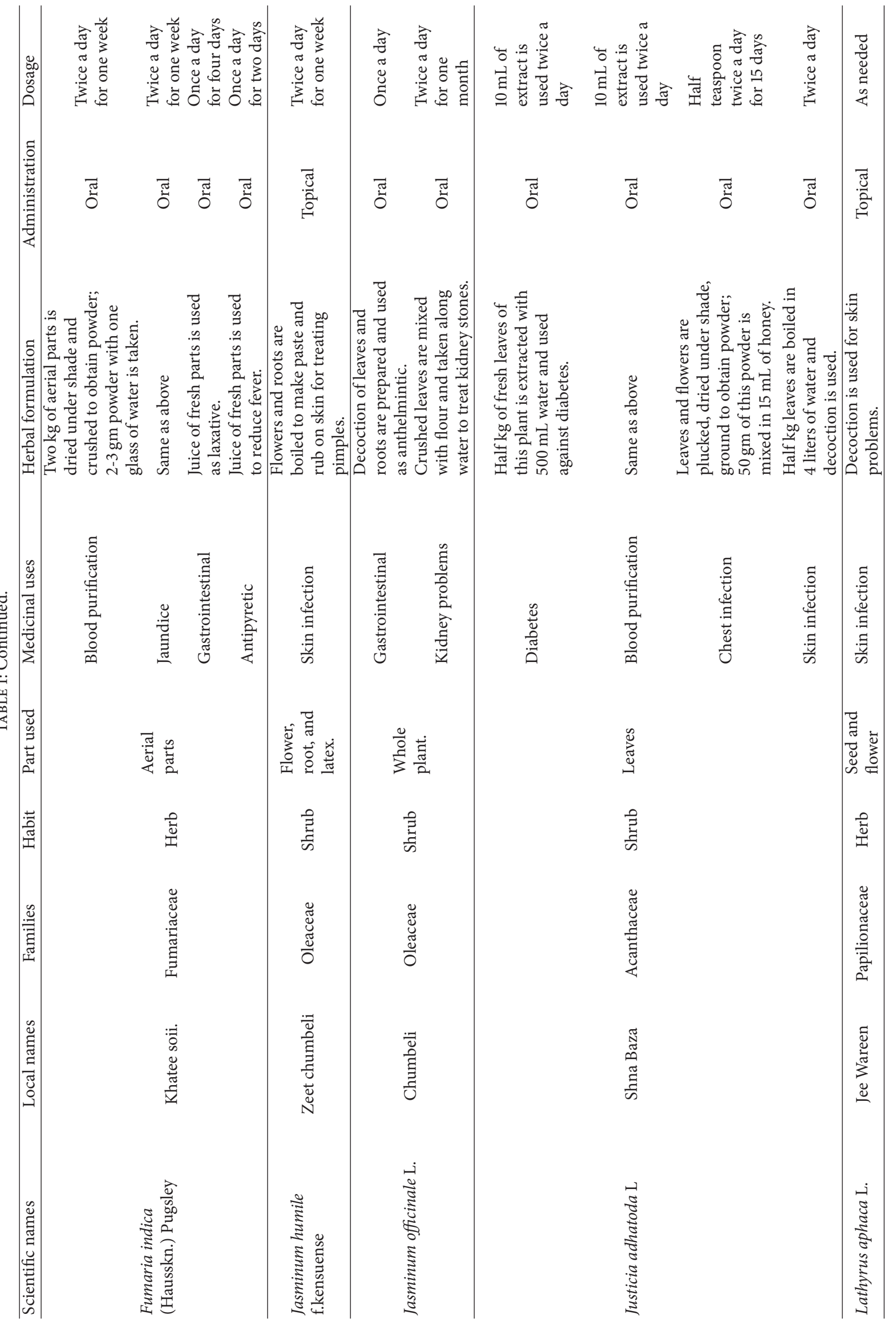



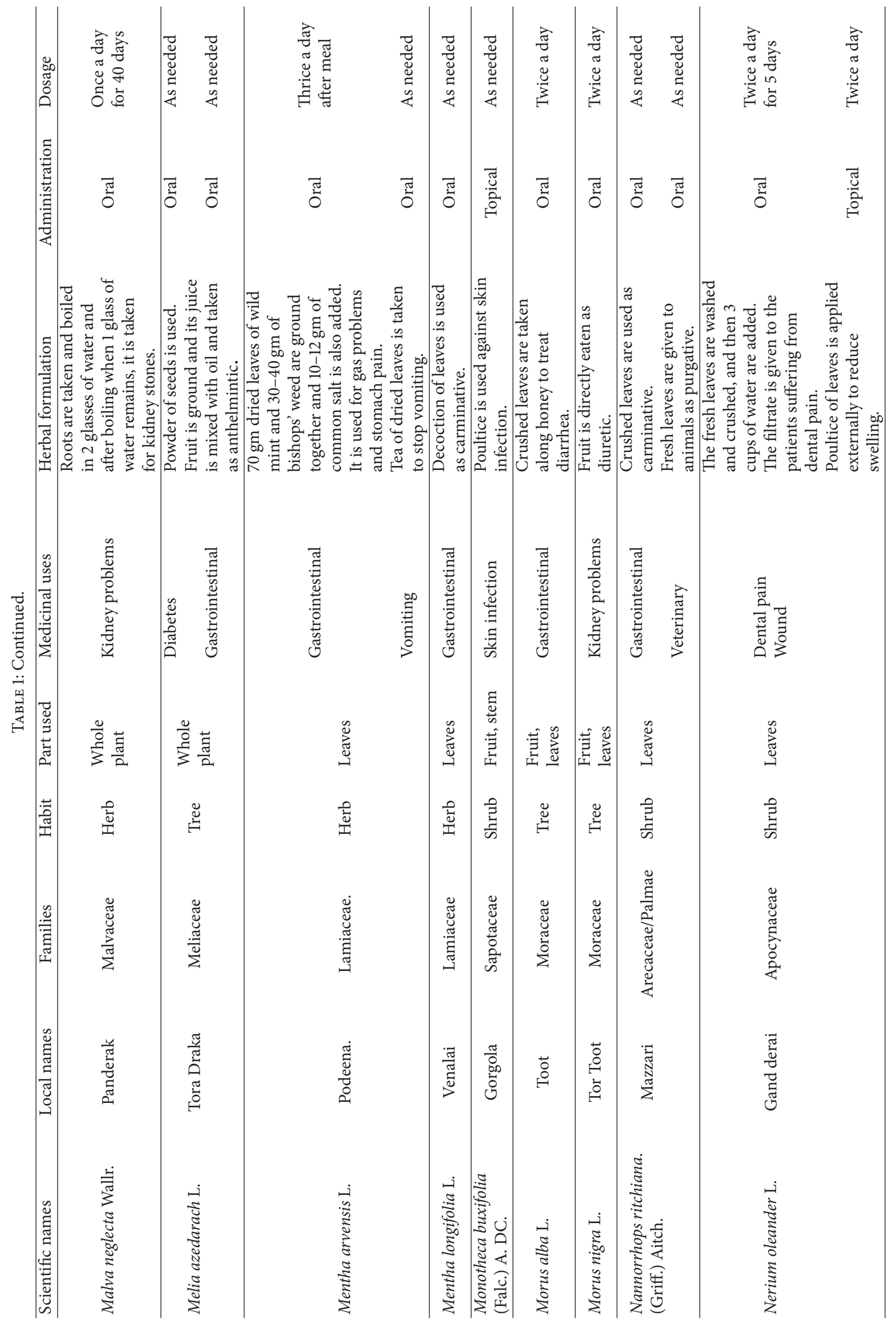


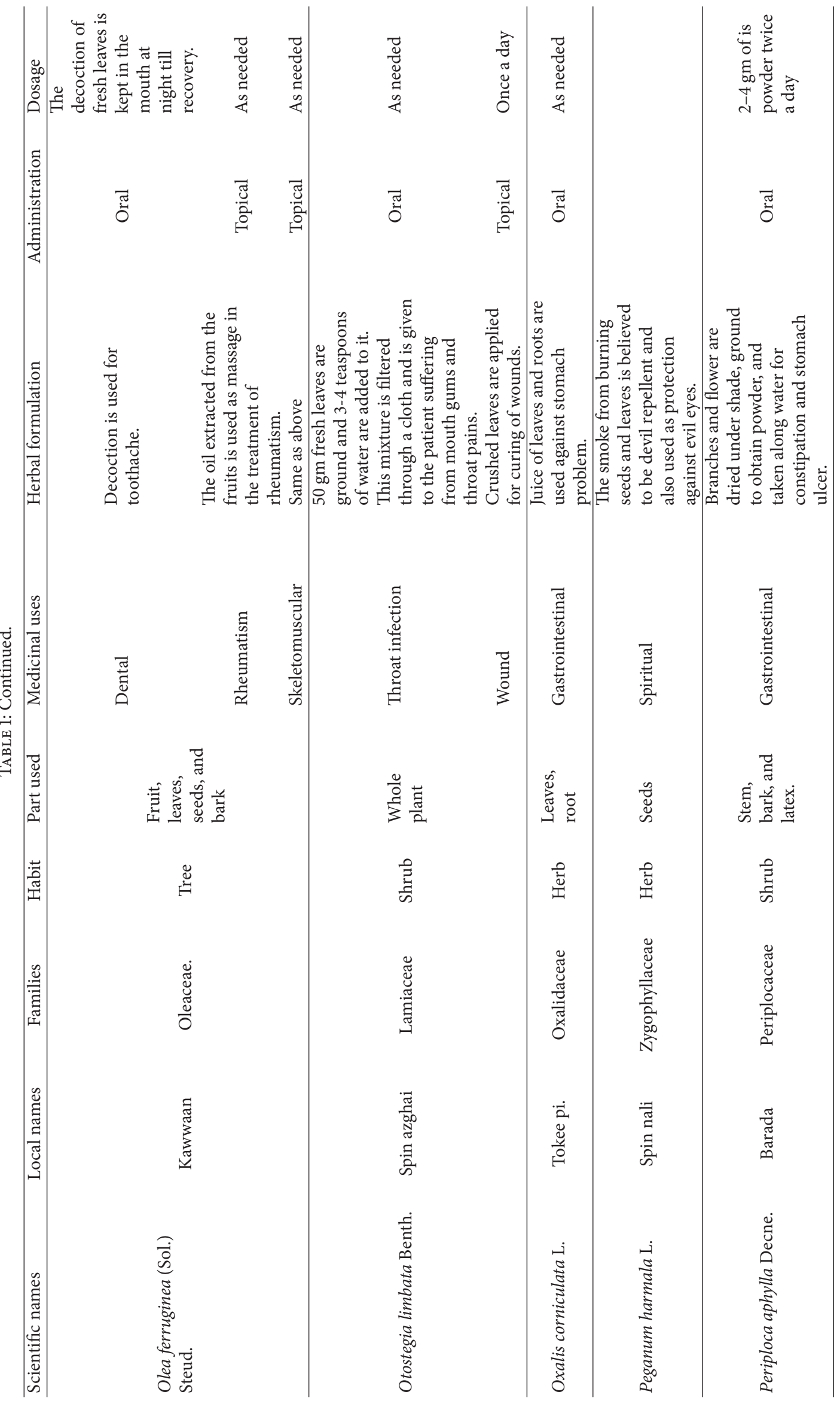




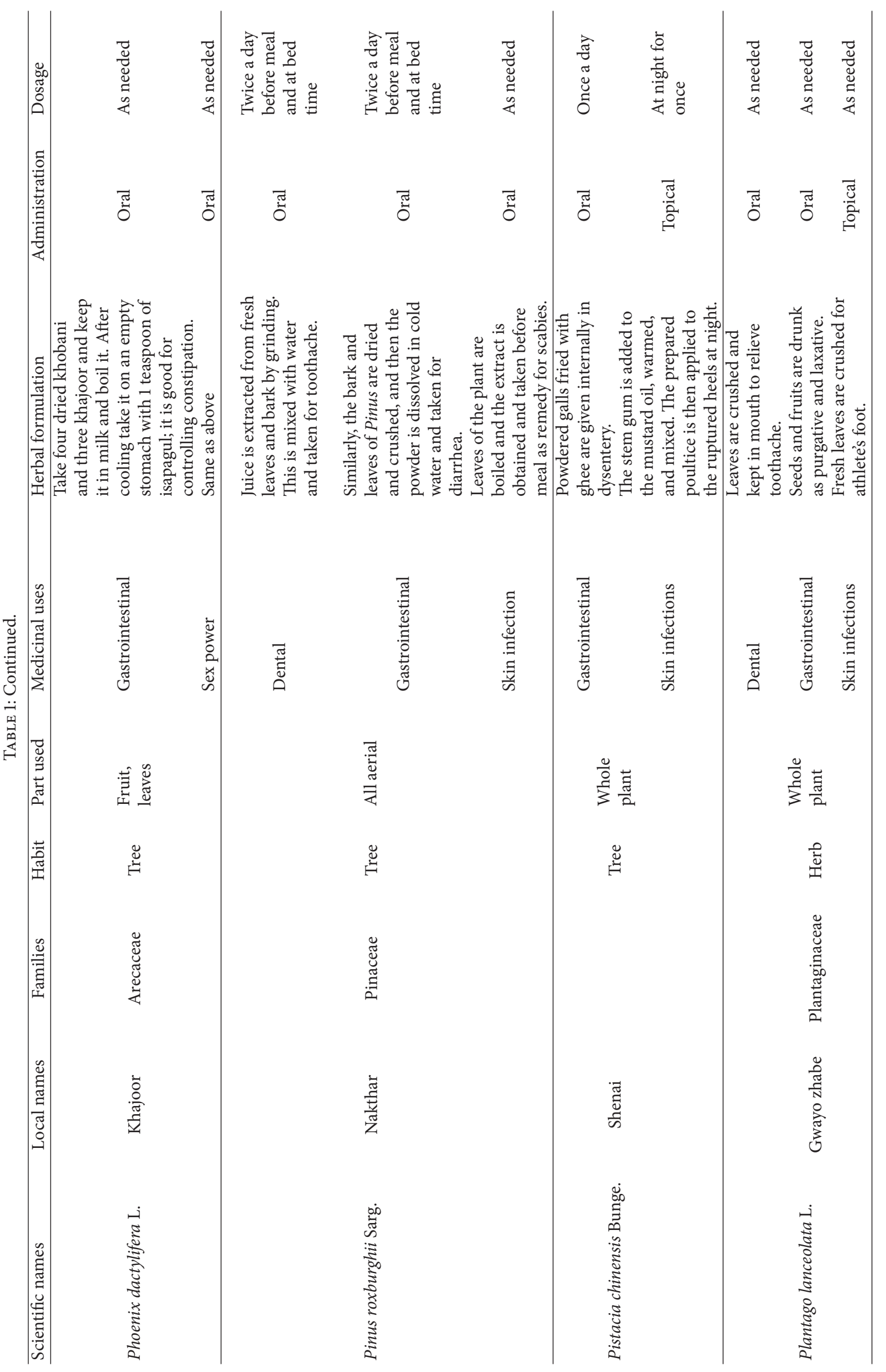




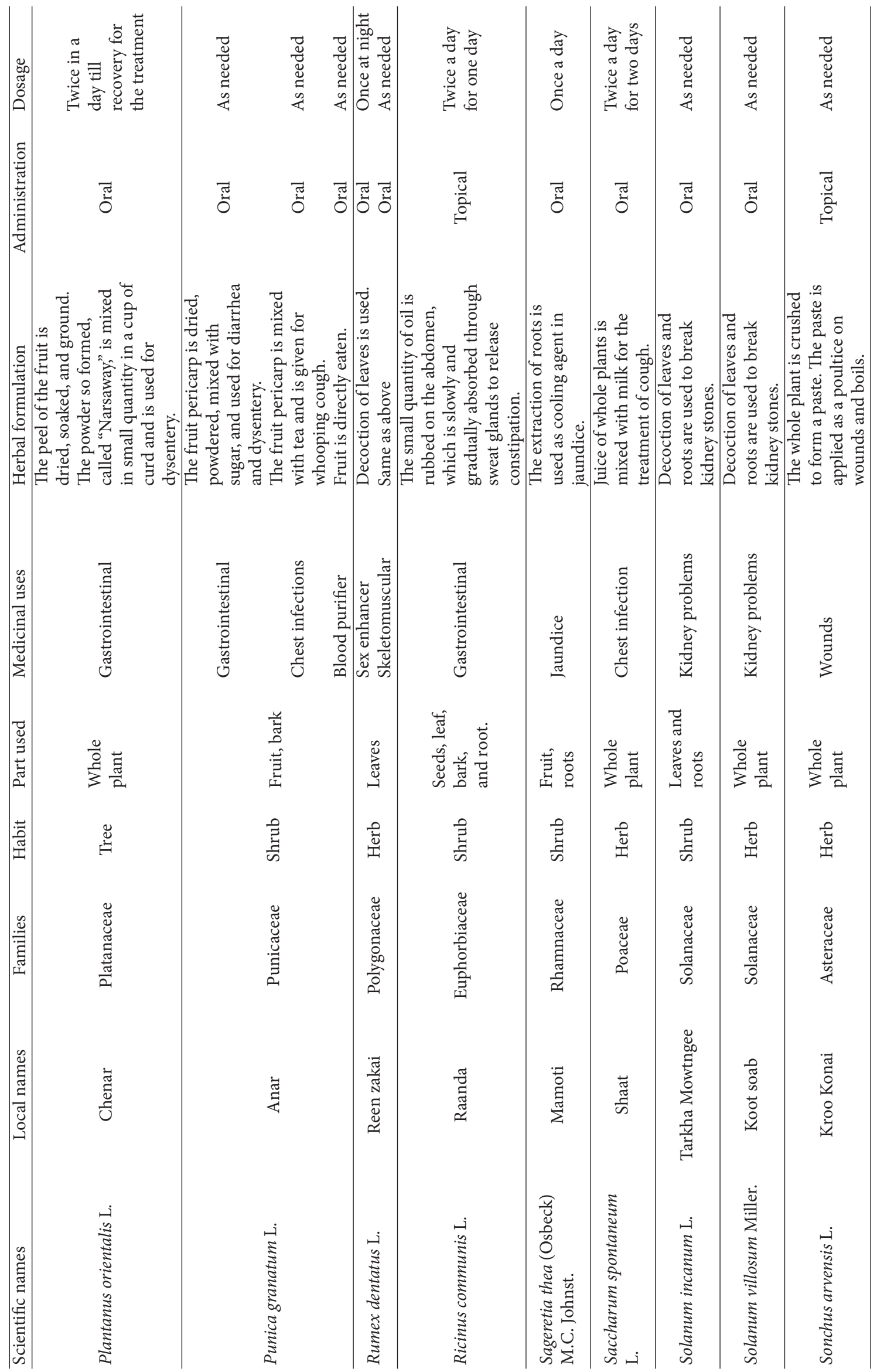




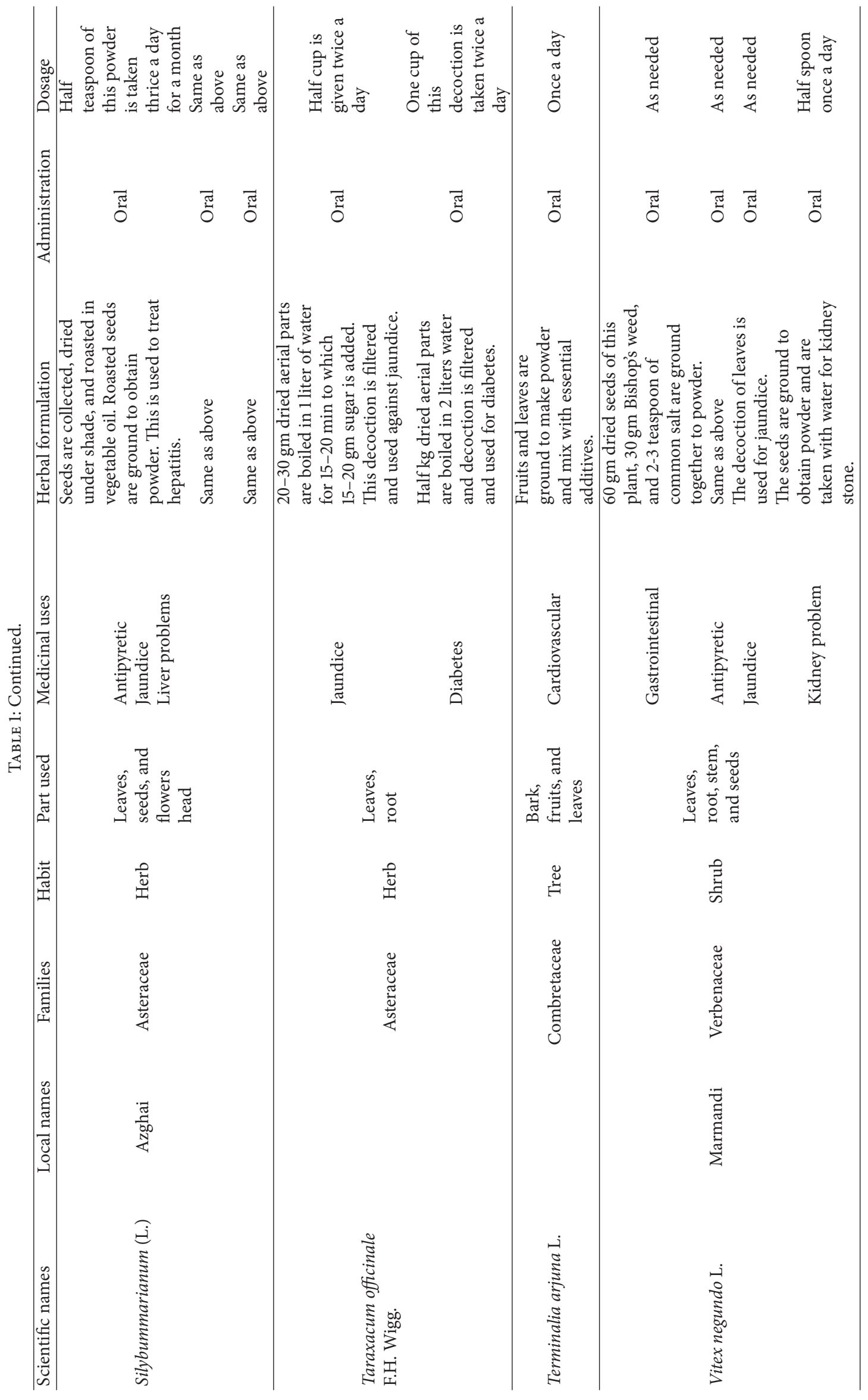




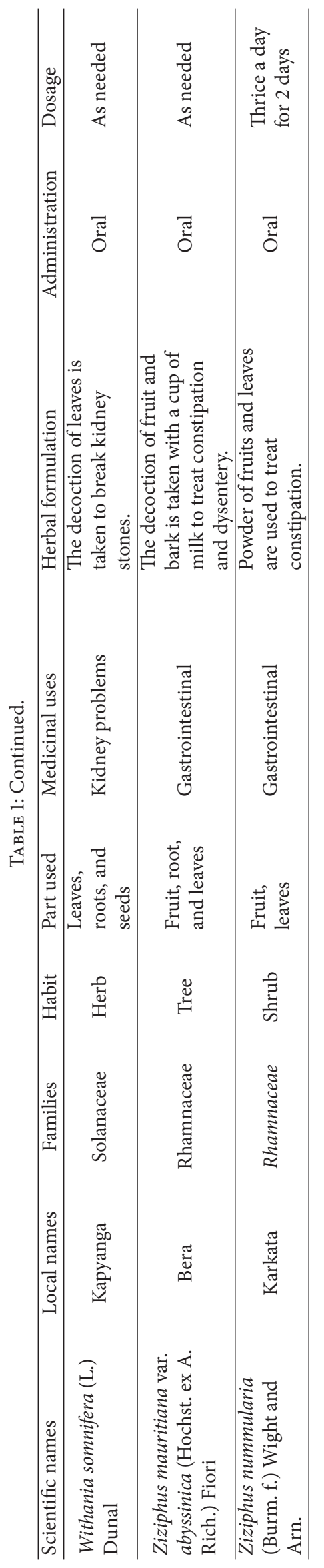


TABLE 2: Fic values of traditional medicinal plants for treating human ailments in district Hangu.

\begin{tabular}{|c|c|c|c|c|}
\hline S. Number & Disease categories & Nur & $\mathrm{Nt}$ & Fic \\
\hline 1 & Gastrointestinal & 200 & 25 & 0.87 \\
\hline 2 & Dermatological & 100 & 13 & 0.87 \\
\hline 3 & Skeletomuscular & 7 & 2 & 0.83 \\
\hline 4 & Blood disorders & 58 & 10 & 0.84 \\
\hline 5 & Chest infections & 24 & 7 & 0.73 \\
\hline 6 & Jaundice & 14 & 7 & 0.53 \\
\hline 7 & Ear nose throat problems & 12 & 3 & 0.81 \\
\hline 8 & Antipyretic & 32 & 7 & 0.80 \\
\hline 9 & Narcotic & 3 & 2 & 0.54 \\
\hline 10 & Sex power & 8 & 3 & 0.71 \\
\hline 11 & Kidney problems & 22 & 7 & 0.71 \\
\hline 12 & Wounds & 3 & 2 & 0.54 \\
\hline 13 & Rheumatism & 9 & 3 & 0.75 \\
\hline 14 & Veterinary & 9 & 3 & 0.75 \\
\hline 15 & Dental & 12 & 4 & 0.71 \\
\hline 16 & Piles & 9 & 3 & 0.75 \\
\hline 17 & Liver problems & 7 & 1 & 1 \\
\hline 18 & Cardiovascular & 9 & 1 & 1 \\
\hline
\end{tabular}

TABLE 3: Fidelity level value of medicinal plants commonly reported against a given ailment.

\begin{tabular}{|c|c|c|c|c|c|}
\hline Number & Medicinal plants & Ailments & lp & $\mathrm{lu}$ & FL value \% \\
\hline 01 & Acacia modesta & Skeletomuscular & 19 & 19 & 100 \\
\hline 02 & Caralluma tuberculata & Antidiabetic & 19 & 19 & 100 \\
\hline 03 & Withania somnifera & Gastrointestinal & 26 & 26 & 100 \\
\hline 04 & Allium sativum & Blood pressure & 18 & 19 & 94.7 \\
\hline 05 & Mentha arvensis & Gastrointestinal & 23 & 25 & 92 \\
\hline 06 & Mentha longifolia & Gastrointestinal & 23 & 25 & 92 \\
\hline 07 & Cannabis sativa & Narcotic & 11 & 12 & 91.6 \\
\hline 08 & Punica granatum & Blood purifier & 21 & 23 & 91.3 \\
\hline 09 & Morus alba & Respiratory tract & 19 & 21 & 90.4 \\
\hline 10 & Morus nigra & Respiratory tract & 19 & 21 & 90.4 \\
\hline 11 & Oxalis corniculata & Gastrointestinal & 17 & 19 & 89.4 \\
\hline 12 & Fagonia indica & Dermatological & 17 & 19 & 89.4 \\
\hline 13 & Fagonia indica & Blood purifier & 26 & 30 & 86.6 \\
\hline 14 & Ricinus communis & Pregnancy & 06 & 08 & 75 \\
\hline 15 & Olea ferruginea & Dermatological & 12 & 16 & 75 \\
\hline 16 & Olea ferruginea & Sore throat & 11 & 15 & 73.3 \\
\hline 17 & Justicia adhatoda & Skeletomuscular & 07 & 10 & 70 \\
\hline 18 & Cuscuta reflexa & Dermatological & 11 & 16 & 68.7 \\
\hline 19 & Ziziphus nummularia & Antidiabetic & 06 & 10 & 60 \\
\hline 20 & Sageretia thea & Antidiabetic & 08 & 14 & 57.1 \\
\hline
\end{tabular}

good rainfall conditions about eight months in the year, the leaves remain green and abundant for most of the months. Our findings of the frequent use of green leaves in the preparation of remedies corroborate the results of $[36,37]$. Traditional healers are involved in preparation of 110 recipes preparation and the major modes of ethnomedicines preparation in the studied region were decoction (20\%), powdering $(20 \%)$, crushing $(12 \%)$, extracting juice $(10 \%)$, and so forth
(Figure 3). Decoction and grinding of medicinal plants for the preparation of ethnomedicines could be due to their high effectiveness for the curing of various ailments. According to Deeba [38], decoction, grinding or crushing, and boiling methods are the most commonly followed methods for the extraction of active compounds. Monotherapy preparations using single medicinal plant were found to be more abundant in comparison with herbal concoction that was prepared by 


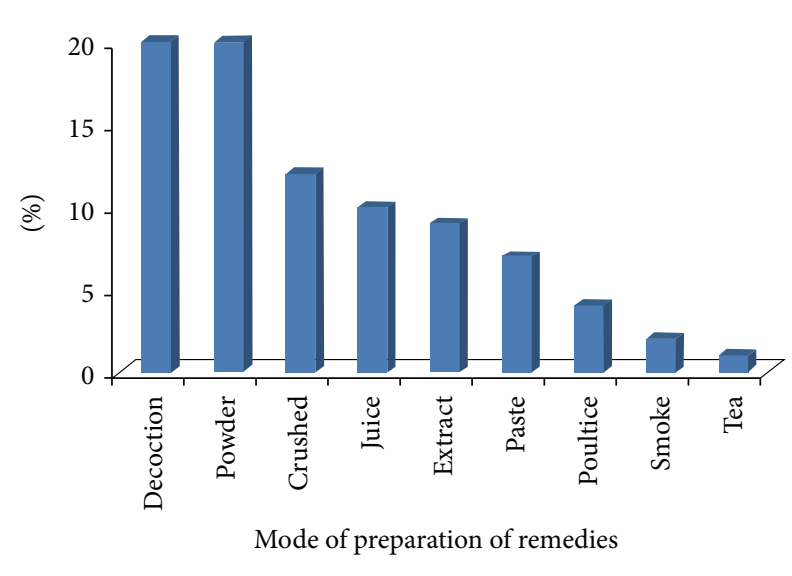

FIGURE 3: Methods of preparation of ethnomedicines.

mixing two or three species; for example, healers take equal amount of extract of onion bulb and mint and mix them for the treatment of cholera. Another example is taking $70 \mathrm{gm}$ dried leaves of wild mint and 30-40 g of "bishops" weed and grinding them together and 10-12 gm of common salt is also added to them and taken for the treatment of gastric problem and stomach pain. The use of mixture of plants has recently been shown to increase the effectiveness of the herbal medicine [39]. Out of total 110 ethnomedicines, 91\% were prepared by using fresh plant materials, whereas $9 \%$ were prepared using dried parts (Table 1). The high usage of freshly prepared ethnomedicines is an indication of the high abundance of medicinal plants in the surrounding areas to be harvested anytime. These findings are in line with other studies conducted in other areas $[40,41]$. The other reason behind the repeated use of fresh plant material could be due to the fact that the drying process contributes to the loss of volatile oil and sometimes due to the fact that high temperature protein becomes denature. Higher use of fresh plant material on the other hand is not a sustainable practice as it may threaten the plants due to recurrent harvesting.

\subsection{Route of Administration and Dosage. The current survey} revealed that most of the plant remedies are taken orally and topically in the investigated region while only single recipe is taken through ear (Table 1). As mentioned earlier, gastrointestinal and skin problems are common in the region and that might be the reason why the majority of the plants are being used orally and topically while some of the plants are being used through ears. Ethnomedicines are taken along different types of additives generally called vectors like honey, salt, sugar, milk, desi ghee, and wheat flour for the purpose of increasing flavor and to reduce the astringent taste of the remedies. This means that since traditional medicines could have sour or bitter tastes in most cases, the additives reduce such tastes and may even improve the efficacy of the medicine. The measurements used to determine the dosages are not standardized and depend on the age and physical appearance of the patient, sociocultural explanation of the illness, diagnosis, and experience of individual herbalist [42].
Mostly the treatment of the patient is completed within a single day or couple of days. When the patients did not show any indication of improvement from their sickness following treatment completion, they were recommended to modern health centres in urban area for further examination by the physician.

4.5. Multipurpose Medicinal Plants and Threats to Their Extinction. The results of the DMR implementation on multipurpose medicinal plants enabled us to recognize which of the multipurpose plants are more under stress in the area and the causes that threaten the plant (Table 4). Accordingly, Olea ferruginea ranked first, Morus alba ranked second, Melia azedarch ranked third, and Acacia modesta ranked fourth while Acacia nilotica ranked fifth. These multipurpose species are basically trees and therefore these species are facing great pressures as the local people are unsustainably harvesting these species for a variety of purposes. The factors responsible for the declining of these species abundance in the area were their overharvesting for agricultural tool, construction, fodder, and fire wood purposes. Beside these major threats, locals of the region also use these plants for handicrafts manufacturing. Free grazing is the common practice in the area. Before the commencement of winter, the grasses are harvested, dried, and put into a stake. The harvesting is done collectively, and then during the bare and cold months of winter, these are fed to the domestic animals. Fuel consumption per home in the studied area is often considered more than the consumption on feeding and other requirements because of severe winters. Thus, the results require urgent conservation strategies to save the declining population of multipurpose plant species in the study region. References $[43,44]$ have also stated the identical pattern of maximum exploitation of multipurpose medicinal plants for uses other than their traditional medicinal importance in southeastern Ethiopia. Traditional healers mostly use the whole plant of these multipurpose species or individual roots (Table 1) of some species for the preparation of ethnomedicinal recipes and this is an unsustainable practice as compared to leaves. Therefore, there is a dire need to take necessary steps for the conservation of these species before their extinction.

4.6. Indigenous Knowledge Associated with Gender, Age, and Socioeconomic Status of the People. Among the 55 informants, $34(61.81 \%)$ were male and $21(38.18 \%)$ were female (Table 5). It is witnessed that males had better knowledge regarding ethnomedicines than females. The reason behind that men have well indigenous knowledge than women might be due to the fact that the men are usually favoured in the shift of the knowledge; however, in many cultures women are responsible for the family's health. The highest number of informants aged above 40 years. The result shows that traditional knowledge is prevalent among the community members; however, it is under threat of transferring to the younger generation to come. The decreasing rate of transfer of indigenous knowledge might be due to the lack of interest among the younger generation to learn and practice it, which might be attributed to the ever increasing influence 


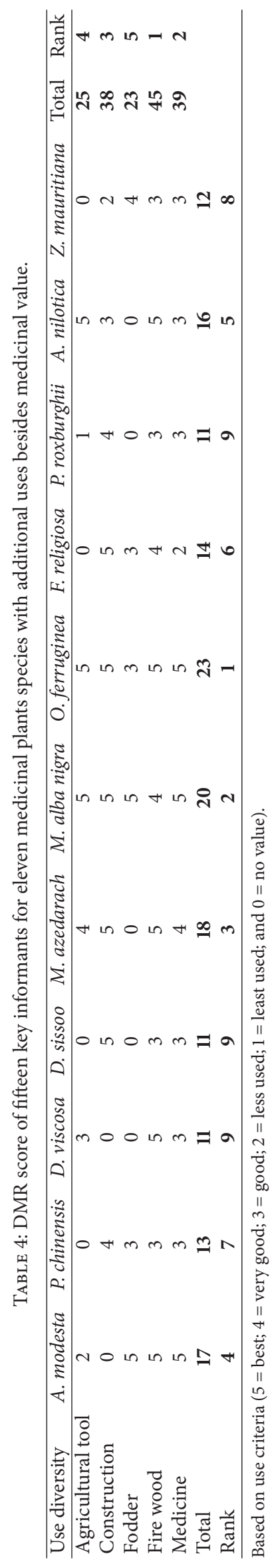


TABLE 5: Gender, age group and literacy level frequencies, and occupation of the interviewed people in the region.

\begin{tabular}{|c|c|c|}
\hline & Total & Percentage \\
\hline \multicolumn{3}{|l|}{ Gender } \\
\hline Male & 34 & 61.81 \\
\hline Female & 21 & 38.18 \\
\hline \multicolumn{3}{|l|}{ Age groups } \\
\hline $20-29$ & 2 & 3.63 \\
\hline $30-39$ & 3 & 5.45 \\
\hline $40-49$ & 7 & 12.72 \\
\hline $50-59$ & 7 & 12.72 \\
\hline $60-69$ & 15 & 27.27 \\
\hline $70-79$ & 12 & 21.81 \\
\hline $80-89$ & 9 & 16.3 \\
\hline \multicolumn{3}{|l|}{ Educational attainment } \\
\hline Illiterate & 25 & 45.45 \\
\hline Primary & 16 & 29.09 \\
\hline Middle & 10 & 18.18 \\
\hline Secondary & 2 & 3.63 \\
\hline University & 2 & 3.63 \\
\hline \multicolumn{3}{|l|}{ Occupation } \\
\hline \multicolumn{3}{|l|}{ Females } \\
\hline House wives & 19 & 90.47 \\
\hline Primary teacher & 2 & 9.52 \\
\hline \multicolumn{3}{|l|}{ Males } \\
\hline Shopkeepers & 10 & 29.4 \\
\hline Farmers & 13 & 38.2 \\
\hline Labours & 6 & 17.6 \\
\hline Primary teachers & 5 & 14.7 \\
\hline
\end{tabular}

of modernization [8]. Almost half of the respondents interviewed were illiterate $(45.45 \%)$, whilst most of those with an education had merely primary $(29.09 \%)$ which reflect the unavailability of standard educational institution in the area (Table 5). Literate people in the study area were found to have less knowledge of medicinal plants as compared to illiterate ones as the former are more likely to be exposed to modernization as also revealed by studies conducted elsewhere $[8,45,46]$. The inhabitants of the study area are not very well off due to less literacy rate and therefore they are heavily dependent on medicinal plants for a variety of purposes in order to compensate their income.

\section{Conclusions}

The present study has recorded 67 medicinal plants used for the treatment of a variety of human ailments in the rural area near Pak-Afghan border region. In the study area herbs constituted the highest proportion of medicinal plants to be utilized. Mostly the leaves of the plants are harvested for different ethnomedicines preparation. Decoction and powdering are the most common methods of drug preparation and remedies are mostly taken orally in the studied region. A high number of plants have been reported to treat gastrointestinal and dermatological problems. The medicinal plants in the region are also facing some threats like unsustainable collection method of some plants, collection for fuel wood, for construction, and for fodder, and agricultural tools. For sustainable utilization of medicinal plants and to avoid further loss, the District Agricultural Office needs to team up with the local people, by providing the community with planting materials of the most threatened and preferred medicinal and multipurpose species so that they can grow them in their home gardens. Moreover, the documented medicinal plants with high degree of consensus can serve as a basis for future investigation of modern drug.

\section{Conflict of Interests}

The authors declare that there is no conflict of interests regarding the publication of this paper.

\section{Authors' Contribution}

Muhammad Adnan and Akash Tariq have designed the research project. Imran Khan conducted the field work and wrote the draft of the paper. Akash Tariq has equally contributed in writing the paper with Imran Khan. Muhammad Adnan, Naser M. AbdElsalam, and Riaz Ullah provided comments on the draft and helped in finalizing the paper. All the authors read and approved the final paper.

\section{Acknowledgments}

The authors are thankful to the Deanship of Scientific Research, King Saud University, Riyadh, Saudi Arabia, for funding the work through the research Group project No RGP-VPP-210. The authors are thankful to the local people for sharing their valuable indigenous knowledge.

\section{References}

[1] D. V. Feo, "Medicinal and magical plants in the northern Peruvian Andes," Fitoterapia, vol. 63, no. 5, pp. 417-440, 1992.

[2] P. Breevort, "The booming U.S. botanical market: a new overview," Herbal Gram, vol. 44, pp. 33-46, 1998.

[3] C. W. Wright, "Plant derived antimalarial agents: new leads and challenges," Phytochemistry Reviews, vol. 4, no. 1, pp. 55-61, 2005.

[4] M. Hamayun, S. A. Khan, H. Y. Kim, and I. J. Leechae, “Traditional knowledge and ex-situ conservation of some threatened medicinal plants of Swat Kohistan," Pakistan Journal of Botany, vol. 38, pp. 205-209, 2006.

[5] S. Hamayun, "Structural diversity, vegetation dynamics and anthropogenic impaction Lesser Himalayan subtropical Forests of Bagh District, Kashmir," Pakistan Journal of Botany, vol. 43, pp. 1861-1866, 2011.

[6] S. Mohammad, Pakistan-Afghanistan: The Conjoined Twins, Department of Embassy of Pakistan, Kabul, Afghanistan, 2010.

[7] R. R. Barnett and S. Abubakar, Resolving Pakistan-Afghanistan Stalemate, United States Institute of Peace, Washington, DC, USA, 2006. 
[8] M. Adnan, I. Ullah, A. Tariq et al., "Ethnomedicine use in the war affected region of northwest Pakistan," Journal of Ethnobiology and Ethnomedicine, vol. 10, article 16, 2014.

[9] N. Akhtar, A. Rashid, B. Murad, and E. Bergmeier, "Diversity and use of ethnomedicinal plants in the region of Swat, North Pakistan," Journal of Ethnobiology and Ethnomedicine, vol. 9, article 25, 2013.

[10] S. Mussarat, N. M. AbdElsalam, A. Tariq, S. M. Wazir, R. Ullah, and M. Adnan, "Use of ethnomedicinal plants by the people living around Indus River," Evidence-Based Complementary and Alternative Medicine, vol. 2014, Article ID 212634, 14 pages, 2014.

[11] I. H. Hassan, W. Murad, A. Tariq, and A. Ahmad, "Ethnoveterinary study of medicinal plants in Malakand Valley, District Dir (Lower), Khyber Pakhtunkhwa, Pakistan," Irish Veterinary Journal, vol. 67, no. 1, article 6, 2014.

[12] S. Begum, N. M. AbdElsalam, M. Adnan, A. Tariq, A. Yasmin, and R. Hameed, "Ethnomedicines of highly utilized plants in temperate Himalaya region," African Journal of Traditional Complementary and Alternative Medicine, vol. 11, no. 3, pp. 132142, 2014.

[13] I. Khan, Ethnobotanical and ecological study of Hangu district, Pakistan [M.S. thesis], Kohat University of Science and Technology, Kohat, Pakistan, 2013.

[14] G. Mustafa, "Education policy analysis report of Khyber Pakhtunkhwa," Tech. Rep., UNESCO, Islamabad, Pakistan, 2009.

[15] G. J. Martin, Ethnobotany: A Method Manual, Chapman \& Hall, London, UK, 1995.

[16] C. M. Cotton, Ethnobotany: Principles and Applications, John Willey \& Sons, Chichester, UK, 1996.

[17] M. Giday, T. Teklehaymanot, A. Animut, and Y. Mekonnen, "Medicinal plants of the Shinasha, Agew-awi and Amhara peoples in northwest Ethiopia," Journal of Ethnopharmacology, vol. 110, no. 3, pp. 516-525, 2007.

[18] R. T. Trotter and M. H. Logan, "Informants consensus: a new approach for identifying potentially effective medicinal plants," in Plants in Indigenous Medicine and Diet, N. L. Etkin, Ed., pp. 91-112, Redgrave, Bedford Hill, NY, USA, 1986.

[19] M. Heinrich, A. Ankli, B. Frei, C. Weimann, and O. Sticher, "Medicinal plants in Mexico: healers' consensus and cultural importance," Social Science and Medicine, vol. 47, no. 11, pp. 1859-1871, 1998.

[20] M. Canales, T. Hernandez, J. Caballero et al., "Informant consensus factor and antibacterial activity of the medicinal plants used by the people of San Rafael Coxcatlán, Puebla, México," Journal of Ethnopharmacology, vol. 97, no. 3, pp. 429439, 2005.

[21] M. Giday, Z. Asfaw, Z. Woldu, and T. Teklehaymanot, "Medicinal plant knowledge of the Bench ethnic group of Ethiopia: an ethnobotanical investigation," Journal of Ethnobiology and Ethnomedicine, vol. 5, article 34, 2009.

[22] J. Friedman, Z. Yaniv, A. Dafni, and D. Palewitch, "A preliminary classification of the healing potential of medicinal plants, based on a rational analysis of an ethnopharmacological field survey among Bedouins in the Negev Desert, Israel," Journal of Ethnopharmacology, vol. 16, no. 2-3, pp. 275-287, 1986.

[23] G. A. Singh, A. Kumar, and D. D. Tewari, "An ethnobotanical survey of medicinal plants used in Terai forest of western Nepal," Journal of Ethnobiology and Ethnomedicine, vol. 8, article 19, 2012.
[24] J. R. S. Tabuti, K. A. Lye, and S. S. Dhillion, "Traditional herbal drugs of Bulamogi, Uganda: plants, use and administration," Journal of Ethnopharmacology, vol. 88, no. 1, pp. 19-44, 2003.

[25] S. K. Uniyal, K. N. Singh, P. Jamwal, and B. Lal, "Traditional use of medicinal plants among the tribal communities of Chhota Bhangal, Western Himalaya," Journal of Ethnobiology and Ethnomedicine, vol. 2, article 14, 2006.

[26] L. R. S. Gazzaneo, R. F. P. Lucena, and U. P. Albuquerque, "Knowledge and use of medicinal plants by local specialists in an region of Atlantic Forest in the state of Pernambuco (Northeastern Brazil)," Journal of Ethnobiology and Ethnomedicine, vol. 1, article 9, 2005.

[27] M. Adnan, S. Begum, A. Latif, A. M. Tareen, and L. J. Lee, "Medicinal plants and their uses in selected temperate zones of Pakistani Hindukush-Himalaya," Journal of Medicinal Plants Research, vol. 6, pp. 4113-4127, 2012.

[28] W. Murad, A. Ahmad, S. A. Gilani, and M. A. Khan, "Indigenous knowledge and folk use of medicinal plants by the tribal communities of Hazar Nao Forest, Malakand District, North Pakistan," Journal of Medicinal Plant Research, vol. 5, no. 7, pp. 1072-1086, 2011.

[29] K. Tolossa, E. Debela, S. Athanasiadou, A. Tolera, and G. Ganga, "Ethno-medicinal study of plants used for treatment of human and livestock ailments by traditional healers in South Omo, Southern Ethiopia," Journal of Ethnobiology and Ethnomedicine, vol. 9, article 32, 2013.

[30] A. Azizullah, M. N. K. Khattak, P. Richter, and D.-P. Häder, "Water pollution in Pakistan and its impact on public health-a review," Environment International, vol. 37, no. 2, pp. 479-497, 2011.

[31] Alamgeer, T. Ahmad, M. Rashid et al., "Ethnomedicinal Survey of plants of Valley Alladand Dehri, Tehsil Batkhela, District Malakand, Pakistan," International Journal of Basic Medical Sciences and Pharmacy, vol. 3, no. 1, pp. 23-32, 2013.

[32] S. K. Bhattacharya, D. Bhattacharya, K. Sairam, and S. Ghosal, "Effect of Withania somnifera glycowithanolides on a rat model of tardive dyskinesia," Phytomedicine, vol. 9, no. 2, pp. 167-170, 2002.

[33] A. Rauf, M. R. Jan, W. U. Rehman, and N. Muhammad, "Phytochemical, phytotoxic and antioxidant profile of Caralluma tuberculata N. E. Brown," Wudpecker Journal of Pharmacy and Pharmacology, vol. 2, no. 2, pp. 21-25, 2013.

[34] T. H. Bekalo, S. D. Woodmatas, and Z. A. Woldemariam, "An ethnobotanical study of medicinal plants used by local people in the lowlands of Konta Special Woreda, southern nations, nationalities and peoples regional state, Ethiopia," Journal of Ethnobiology and Ethnomedicine, vol. 5, article 26, 2009.

[35] E. Lulekal, Z. Asfaw, E. Kelbessa, and V. P. Damme, "Ethnomedicinal study of plants used for human ailments in Ankober District, North Shewa Zone, Amhara Region, Ethiopia," Journal of Ethnobiology and Ethnomedicine, vol. 9, article 63, 2013.

[36] C. P. Kala, "Ethnomedicinal botany of the Apatani in the Eastern Himalayan region of India," Journal of Ethnobiology and Ethnomedicine, vol. 1, article 11, 2005.

[37] J. A. Bhat, M. Kumar, and R. W. Bussmann, "Ecological status and traditional knowledge of medicinal plants in Kedarnath Wildlife Sanctuary of Garhwal Himalaya India," Journal of Ethnobiology Ethnomedicine, vol. 9, article 1, 2013.

[38] F. Deeba, Documentation of ethnoveterinary practices in urban and peri-urban areas of Faisalabad, Pakistan [Ph.D. thesis], University of Agriculture, Faisalabad, Pakistan, 2009. 
[39] S. Zonyane, S. F. van Vuuren, and N. P. Makunga, "Pharmacological and phyto-chemical analysis of a medicinal plant mixture that is used as traditional medicine in Western Cape," in Proceedings of the 38th Annual Conference of the South African Association of Botanist, p. 124, University of Pretoria, Pretoria, South Africa, January 2012.

[40] S. Ignacimuthu, M. Ayyanar, and K. Sivaraman, "Ethnobotanical investigations among Tribes in Madurai District of Tamil Nadu (India)," Journal of Ethnobiology and Ethnomedicine, vol. 2, article 25, 2006.

[41] R. W. Bussmann and D. Sharon, "Traditional medicinal plant use in Loja Province, Southern Ecuador," Journal of Ethnobiology and Ethnomedicine, vol. 2, article 44, 2006.

[42] A. Jabbar, M. A. Raza, Z. Iqbal, and M. N. Khan, "An inventory of the ethnobotanicals used as anthelmintics in the southern Punjab (Pakistan)," Journal of Ethnopharmacology, vol. 108, no. 1, pp. 152-154, 2006.

[43] Z. Sher, D. Z. Khan, and F. Hussain, "Ethnobotanical studies of some plants of Chagharzai Valley, District Buner, Pakistan," Pakistan Journal of Botany, vol. 43, no. 3, pp. 1445-1452, 2011.

[44] H. Yineger, E. Kelbessa, T. Bekele, and E. Lulekal, "Ethnoveterinary medicinal plants at Bale Mountains National Park, Ethiopia," Journal of Ethnopharmacology, vol. 112, no. 1, pp. 5570, 2007.

[45] T. Gedif and H. Hahn, "The use of medicinal plants in self-care in rural central Ethiopia," Journal of Ethnopharmacology, vol. 87, no. 2-3, pp. 155-161, 2003.

[46] J. W. Bastien, "Exchange between Andean and Western medicine," Social Science and Medicine, vol. 16, no. 7, pp. 795803, 1982. 


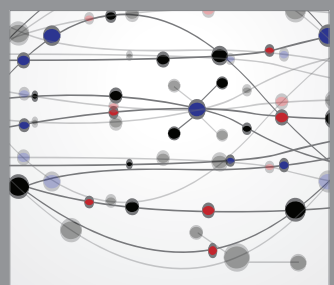

The Scientific World Journal
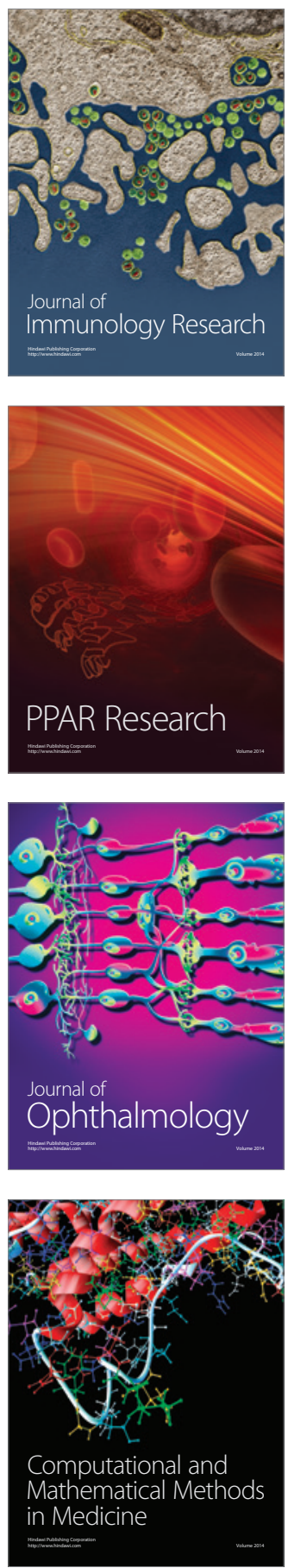

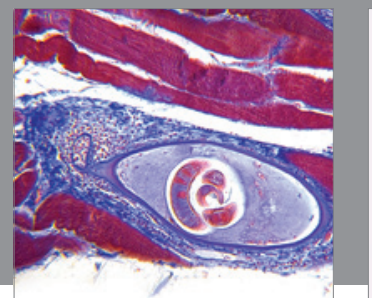

Gastroenterology

Research and Practice
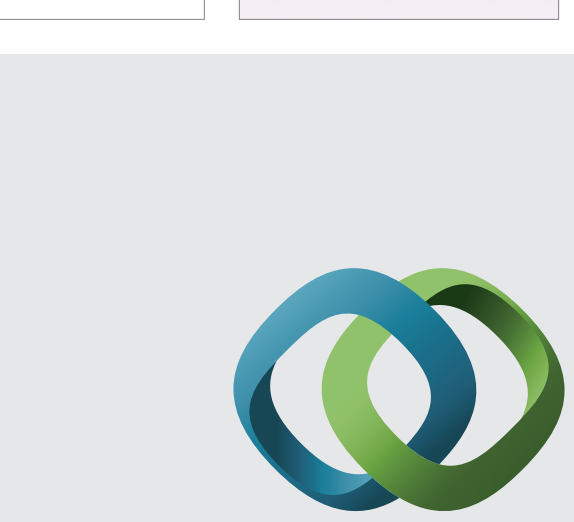

\section{Hindawi}

Submit your manuscripts at

http://www.hindawi.com
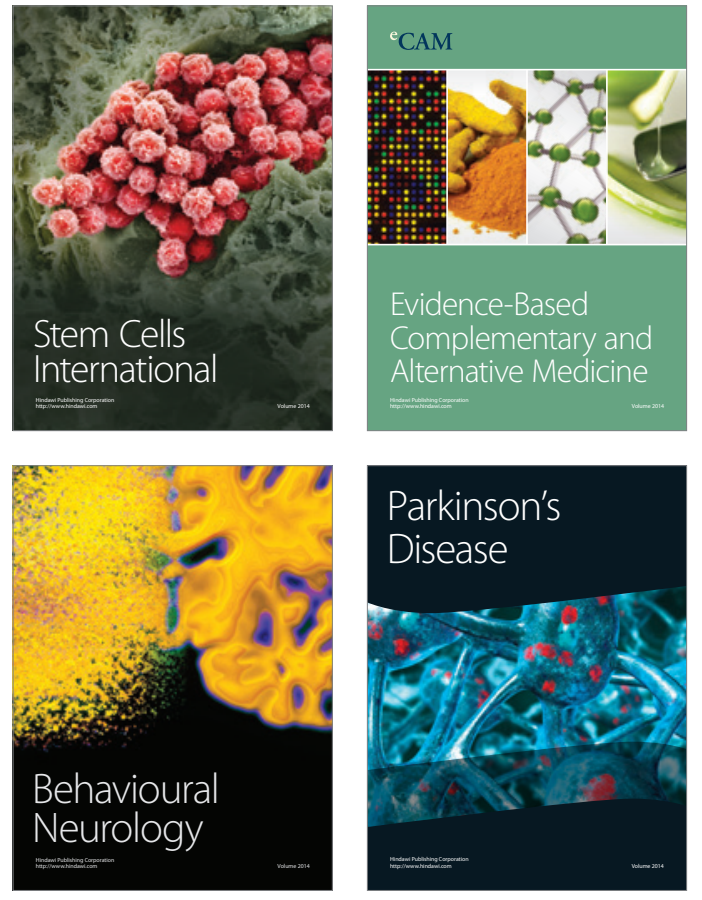
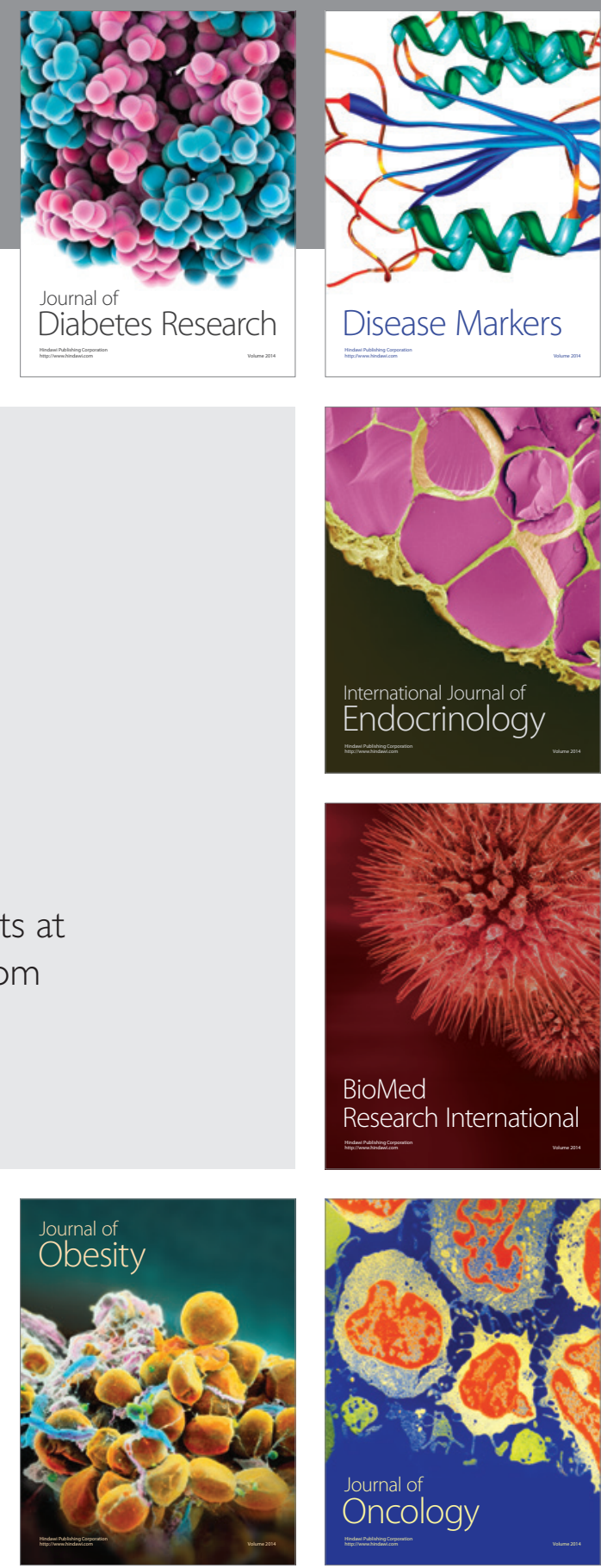

Disease Markers
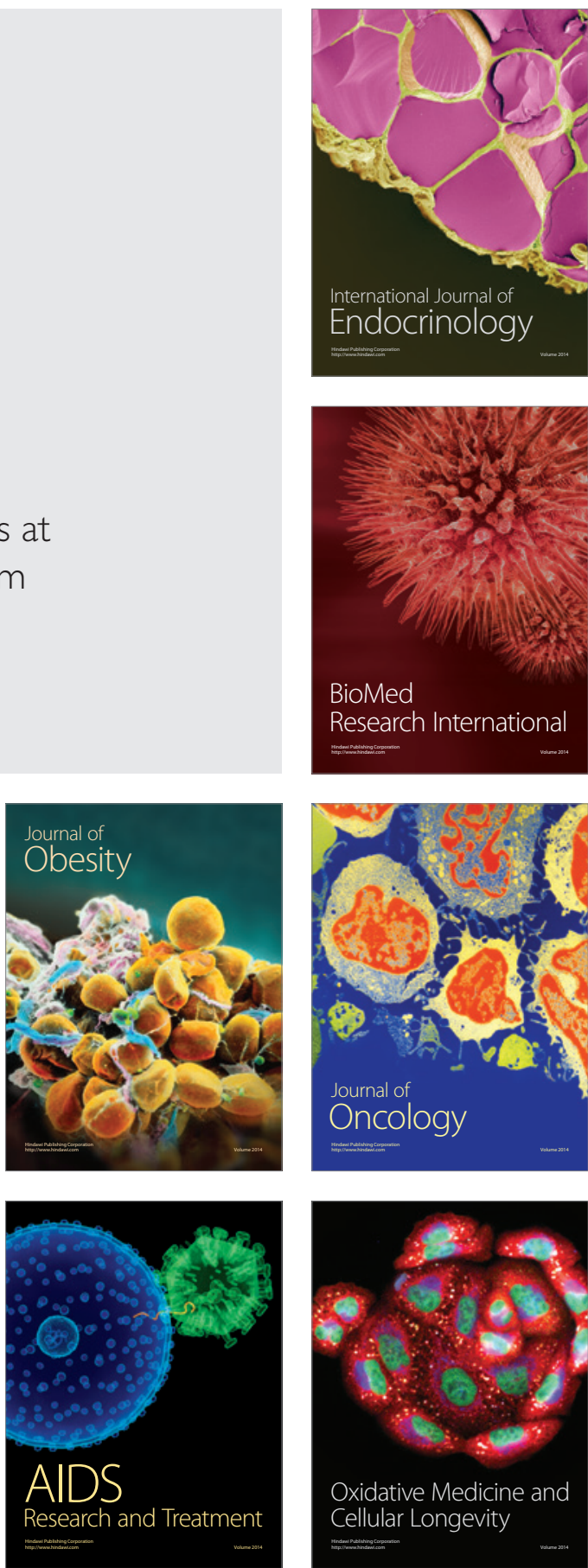